\title{
Growth Model of the New Member States: Challenges and Prospects
}

\author{
This paper reviews the strong pre-crisis economic growth in the new EU member states \\ and assesses whether the growth model can continue to be successful after the crisis. The \\ analysis shows that a new growth model for the region will be needed, ideally one that focuses \\ on raising domestic savings, implementing structural reforms to increase potential growth and \\ rebalancing growth towards tradable sectors.
}

High economic growth in the new EU member states (at least in the so-called transition countries) for more than a decade and the region's resultant strong real economic convergence path with the old EU member states (EU15) was without precedent. The extraordinarily high rate of growth can be attributed to a special growth model which distinguishes the growth achievements of the region. ${ }^{1}$ The global financial and economic crisis, however, hit most of the new member states (EU10) harder than other countries in the world, and post-crisis recovery has been generally slower than in other emerging economies. This raises questions about the region's unique pre-crisis development model. This paper will address three main questions. First, what are the special features of the EU10's growth model that distinguish the growth achievements of the region? Second, can post-crisis recovery and growth be achieved with the same growth model that was employed in the pre-crisis period, i.e. is the model sustainable over the longer term? And finally, can the EU10 once again achieve faster growth than the EU15 and thus continue the convergence trend? If not, does the growth model need revisions or should it be replaced altogether?

In order to answer these questions, we provide a detailed analysis of the period following the transformational recession as a first step. We review the development of poten-

* This research was carried out under the Bolyai János Kutatási Ösztöndíj programme of the Hungarian Academy of Sciences.

1 T. Becker, D. Daianu, Z. Darvas, V. Gligorov, M. Landesmann, P. Petrovic, J. Pisani-Ferry, D. Rosati, A. Sapir, B. Weder d Mauro: Whither growth in central and eastern Europe?, Policy lessons for an integrated Europe, Bruegel Blueprint Series, Vol. XI, 2010; R. Atoyan: Beyond the Crisis: Revisiting Emerging Europe's Growth Model, IMF Working Paper, WP/10/92, 2010; S. Fabrizi o, D. Leigh, A. Mody: The Second Transition, in: European Economy, No. 366, March 2009.

Andrea Elekes, University of Pannonia, Hungary.

Péter Halmai, University of Pannonia, Hungary. tial growth in the EU10, applying a production function approach and growth accounting. ${ }^{2}$ The analysis is based on the AMECO and the EPC's Output Gap Working Group databases. We formed three subgroups within the EU10, taking geographic location and development paths and structures into account as classification criteria: the Central European countries (CE5), consisting of the Czech Republic (CZ), Hungary $(\mathrm{HU})$, Poland $(\mathrm{PL})$, Slovenia $(\mathrm{SL})$ and Slovakia $(\mathrm{SK})$; the Baltic countries (B3), made up of Estonia (EE), Lithuania (LT) and Latvia (LV); and the South-eastern European countries (SE2), Bulgaria (BG) and Romania (RO). The next step is to identify the common features of the region's growth performance and construct a theoretical model (a system of common features). After that we will examine how the crisis affected this growth model.

\section{Pre-crisis development of potential growth and its factors}

The rate of potential growth increased in the EU10 in the years following the transformation crisis (see Table 1). In sum, we can state that the dominant factors of the EU10's potential growth were capital accumulation and the improvement of the total factor productivity. The dynamism of the latter, however, had almost halved even before the onset of the financial crisis.

The main potential growth features in the years preceding the 2008-2009 crisis were the following:

- Having got through the transformation crisis (from 1996 onwards), the average rate of potential growth in

2 For methodological details see C. Denis, D. Grenouilleau, K. McMorrow, W. Röger: Calculating potential growth rates and output gaps - a revised production function approach, European Economy Economic Papers, No. 247, European Commission, 2006; F. D'Auria, C. Denis, K. Havik, K. McMorrow, C. Planas, R. Raciborski, W. Röger, A. Rossi: The production function methodology for calculating potential growth rates and output gaps, European Economy Economic Papers, No. 420, July 2010. 
Table 1

Pre-crisis development of potential growth and its factors in \%

\begin{tabular}{lcccccccccccccccc}
\multicolumn{1}{c}{} & \multicolumn{1}{c}{ Potential Growth } & \multicolumn{1}{c}{ Contribution of different factors to potential growth } \\
& 1996 & 2000 & 2004 & 2007 & 1996 & 2000 & 2004 & 2007 & 1996 & 2000 & 2004 & 2007 & 1996 & 2000 & 2004 & 2007 \\
\hline EU15 & 2.1 & 2.5 & 2.0 & 1.8 & 0.2 & 0.4 & 0.4 & 0.3 & 0.7 & 0.9 & 0.7 & 0.9 & 1.2 & 1.2 & 0.8 & 0.6 \\
\hline EU10 & 3.6 & 3.2 & 3.7 & 4.5 & -0.3 & -1.0 & 0.1 & 0.7 & 1.7 & 1.8 & 1.5 & 2.2 & 2.1 & 2.4 & 2.3 & 1.6 \\
\hline CE5 & 3.8 & 3.2 & 3.8 & 4.3 & -0.3 & -1.1 & 0.1 & 0.8 & 1.9 & 1.9 & 1.4 & 1.9 & 2.1 & 2.3 & 2.2 & 1.6 \\
\hline B3 & 3.5 & 3.9 & 6.5 & 5.8 & -1 & -1.1 & 0.9 & 0.4 & 1.3 & 1.9 & 3.0 & 3.8 & 3.2 & 3.1 & 2.5 & 1.5 \\
\hline SE2 & 2.3 & 2.9 & 4.3 & 5.3 & -0.4 & -0.6 & -0.3 & 0.1 & 1.0 & 1.0 & 1.8 & 3.3 & 1.6 & 2.4 & 2.8 & 1.8 \\
\hline EU27 & 2.2 & 2.6 & 2.1 & 2.0 & 0.2 & 0.3 & 0.4 & 0.3 & 0.7 & 0.9 & 0.8 & 1.0 & 1.3 & 1.3 & 0.9 & 0.7 \\
\hline
\end{tabular}

Source: own calculation.

the EU10 was above the EU15 average. This demonstrates significant catching-up performance and the advancement of real convergence.

- There are significant differences within the EU10 (see Table 1). Potential growth of the CE5 countries was close to the EU10 average throughout the entire examined period. The growth performance of the B3 countries was outstanding through 2007; indeed, they exceeded the EU10 average by more than $50 \%$ in certain years. The SE2 countries did not exceed the EU10 average until 2003, as transformation and macroeconomic problems limited their catching up until that time. The dynamism of their potential output exceeded the EU10 and CE5 averages.

- Until 2004, labour's contribution to potential GDP in the EU10 was negative. This was mainly due to the deep structural changes. As regards structural unemployment (NAIRU), the change took place in the reverse direction. The growth of structural unemployment was especially high in B3 and SE2 countries through 2003.

- Contribution of capital correlates strongly with the development of the investment rate. The increasing level of the latter in the EU10 is mainly the result of foreign capital inflow. Having got through the transformation crisis, the integration "anchor" played a decisive role in increasing the capital-attracting ability of the countries concerned. There was a strong increase in capital accumulation, too - its contribution to potential GDP since 2005 had the highest ratio.

- Total factor productivity can rise at an unusually high rate during a period of transition to a market economy (this is known as transition buoyancy). The strong European adaptation process (institutionalisation and activating the "integration anchor") has had a similar im- pact on the countries concerned. This dynamism may exceed the EU10 average in the countries starting off at a lower level of development. However, total factor productivity (TFP) growth dynamism had already decreased before the outbreak of the financial and economic crisis. (In the period 2003-2008, the decrease of TFP growth was compensated for by robust foreign capital inflows and a temporary increase in the contribution by capital accumulation.) At the same time, the drop in TFP growth was continuous and seemingly unstoppable in the EU15 countries, too. TFP is a decisive structural factor of long-run productivity. The depletion of TFP growth had already foreshadowed the erosion of the European growth potential before the outbreak of the crisis.

\section{The pre-crisis growth model}

Compared to other emerging regions, the EU integration anchor seems to be the most important distinguishing factor of the EU10's growth model. There are two main channels through which integration has exercised its influence: first, the prospect of integration increased confidence in EU10 economies and reduced their perceived risk; second, the countries committed themselves to European norms, which contributed to an improvement of economic efficiency.

International financial integration

Investment and overall capital deepening was one of the most important factors of high potential growth in the EU10 countries. Their entry into the EU was accompanied by the liberalisation of their capital markets, which led to extensive capital flows. Foreign banks that established subsidiaries and branches in the region served as conduits of foreign capital for extensive lending to domestic businesses and households. As macroeconomic conditions improved, country risks decreased, so the region's countries (and larger cor- 
porations) were able to borrow on international capital markets at increasingly lower spreads. Consequently, financing costs significantly decreased (often below the economically justified level). As a result of the significant capital inflow, the contribution of capital to potential growth in the EU10 increased from 1.7\% in 1996 to $2.2 \%$ in 2007 (see Table 1). The investment rate also increased significantly, from just over $20 \%$ to $27.4 \%$ by 2008 .

The investment rate in the CE5 countries approaches the average of the EU10. The rate was moderately higher than the EU10 average until 2002, after which it began to lag behind (see Table 1). The investment rate in the B3 countries increased over this time period due to the particularly high rate of capital inflow - from $15.3 \%$ in 1996 to $26.6 \%$ in 2004 . The contribution of capital accumulation rose from $1.3 \%$ to $3.0 \%$ in the same period in this region. EU accession, the declining risk premium and the favourable international investment environment resulted in an exceptionally high investment ratio. This ratio rose to $35 \%$ by 2007 , and the contribution of capital increased to $3.8 \%$. Capital inflow provided full compensation for the declining transition buoyancy of total factor productivity in the B3 countries.

Capital accumulation was an important factor in improving labour productivity in the SE2 countries. The rate of capital accumulation - just $16 \%$ - at the end of the 1990 s was without precedent, even if we take into account the low development level of these countries. A low level of foreign capital inflow was one of the most important explaining factors. Therefore, the contribution of capital remained low in this period (about $0.8 \%$ per year). Concurrent with the EU adaptation process, the investment ratio grew quickly beginning in 2000. In 2004 it was above the EU10 average, and by 2008 it had reached the extraordinarily high level of $37.4 \%$. Capital's contribution exceeded $3 \%$ of potential GDP in this period, making it the most important potential growth factor in the SE2 countries between 2006 and 2008.

\section{Human capital}

The low relative unit labour costs and relatively well-educated human capital made the EU10 region attractive to foreign investors. This led to rapid technology transfer, access to high-income markets and the possibility of integrating into cross-border production networks. ${ }^{3}$ All of these factors resulted in improved labour productivity.

The rising rate of potential growth through 2005 can be explained exclusively by this labour productivity increase. The dynamism of labour productivity far exceeded the decrease

3 M.A. Landesmann: Which Growth Model for Central and Eastern Europe after the Crisis?, FIW Policy Brief, No. 4, 2010. in labour supply caused by structural changes in these economies. As Table 1 shows, the contribution of labour has had a positive sign and has been significant since 2005 (0.5- $0.7 \%$ of potential GDP). At the same time, the increase in labour productivity slowed down. Structural unemployment increased until 2003 and then declined by $3.7 \%$ by 2008 .

In the B3 countries, the faster labour productivity growth far exceeded the decreasing contribution of labour until 2002. The increase in the structural unemployment rate was dramatic: it rose from $5 \%$ to $12.9 \%$ by 2002 . The trend reversed in 2003, and the NAIRU declined to 8.7\%. From 2003 to 2007 the high rate of labour productivity growth was accompanied by a rise in labour's contribution to potential GDP $(0.4-1.1 \%$ per year). In the SE2 countries, labour's contribution to potential GDP decreased until 2006, but this was compensated for by the improving productivity. Structural unemployment increased until 2003 (from 6.8\% to 8.8\%) and then decreased through 2008 , when it was at $7.1 \%$.

\section{TFP growth}

A 2008 World Bank study highlights TFP's decisive role in the region's growth. ${ }^{4}$ While it is true that in the period 19952005 the EU10 had the third-highest TFP growth in the world (after China and the Commonwealth of Independent States), our analysis shows that there was a remarkable decrease in TFP's contribution to potential growth. It dropped from $2.4 \%$ in 2000 to $1.3 \%$ in 2008 (see Table 1). Therefore, we can argue that in the most successful period of convergence (20042008), it was capital and not TFP that drove the growth.

In the first years of the B3 region's transition to a market economy, the contribution of total factor productivity increased notably, exceeding 3\% per year in the period 19962001 before gradually decreasing to $1.1 \%$ by 2008 . The TFP increase in the SE2 region picked up only at the end of the 1990s once the market economy there had grown more developed.

\section{External liberalisation}

The EU10 can be characterised by a very high degree of external liberalisation. Trade opening occurred relatively quickly in the region. The new member states followed the globalisation trend: trade growth was faster than production growth. In 1995 the ratio of trade (exports and imports) to GDP was below $100 \%$ in half of the examined countries. By 2007 only two such countries (Poland and Romania) remained. Growth of the trade-to-GDP ratio surpassed $20 \%$ in nine countries. Openness is also reflected in market shares,

4 World Bank: Unleashing Prosperity - Productivity Growth in Eastern Europe and the former Soviet Union, Washington DC 2008. 
and this is a region-specific feature. The market share of the region has increased in spite of the rapid appreciation of its national currencies. This can be traced back to deep overall structural reforms. The rise in exports was due to technological development and quality improvement. The EU10 countries were generally much more open than other emerging regions or the EU15. However, there were large differences between the country groups. The CE5 group turned out to be successful in this opening process, as it did not generate strong structural imbalances (in trade and current accounts or in growing private sector savings-investment gaps) prior to the crisis. This was quite different in the B3 and SE2 groups, where unsustainable imbalances developed due to the historical weaknesses of the tradable sectors, choices made with regard to exchange rate regimes, the importance of remittances and because of missing instruments to deal with cross-border financial market integration. ${ }^{5}$

\section{Catching-up potential}

Liberalisation and openness in external economic relations coincided with a classic process of convergence. Growth rates in the region were substantially above those of their western neighbours, even though these catching-up processes were at times interrupted by economic policy missteps or by misalignments of wages and productivity. ${ }^{6}$

\section{Sustainability challenges}

The previous section suggests a link between the region's growth model and the build-up of vulnerabilities and inherent challenges. These vulnerabilities and challenges may call into question the sustainability of the EU10 growth model. The rapid rate of growth was achieved at the expense of an accumulation of large external liabilities, which spilled over into large current account deficits. Moreover, there were several transitional elements of growth. With this in mind, we now offer an overview of the aforementioned vulnerabilities following the factors of the pre-crisis growth model.

\section{Net capital inflow}

Capital inflow and credit expansion were crucial drivers of economic growth but also key factors in the region's vulnerability. While capital inflows to emerging markets generally boost growth, signalling market confidence in the fundamentals of economy, sudden surges can also create financial and

5 For details see M.A. Landesmann,op. cit.

6 For details see e.g. P. Halmai, V. Vásáry: Real convergence in the new Member States of the European Union: Shorter and longer term prospects, in: The European Journal of Comparative Economics, Vol. 7 , No. 1, 2010, pp. 229-253; P. Halmai, V. Vásáry: Convergence Crisis? Economic Crisis and Convergence in the European Union, in: International Economics and Economic Policy, Vol. 9, No. 3, 2012, pp. 297-322. economic risks and complicate macroeconomic management.

While the inflow of foreign direct investment (FDI) was a key driver of economic growth in the EU10 region, the composition of FDI was not always favourable. In particular, the share flowing to manufacturing, the key sector for developing export potential, was significant only in the CE5. To the extent that foreign investment was (at least partly) channelled into consumption and housing loans, one cannot exclude the possibility of a misallocation of resources. Resources were diverted away from investment in the tradable sector, which was bound to negatively affect competitiveness and growth. Therefore, financial deepening fuelled the absorption-led growth and exacerbated the (often already pronounced) non-tradable sector bias in the structure of the most vulnerable economies. ${ }^{7}$

Other investment flows (mostly constituting cross-border loans) were more volatile, but in the peak years before the financial crisis, their magnitude even exceeded FDI inflows. EU accession and the prospect of joining the single currency significantly mitigated the risk premia. In the new member states, the sovereign credit risk ratings continued to improve both before and after accession. ${ }^{8}$ The process often led to negative real interest rates, especially when accompanied by strong inflation and rapid credit expansion. The abundant, but ultimately unsustainable, capital inflows that bridged increasing gaps between spending and incomes fuelled credit booms and resulted in the accumulation of foreign liabilities. ${ }^{9}$ What is more, the credit boom fostered primarily domestic demand, which is associated with the overheating of the economies.

The pre-crisis credit growth process in the region has been extensively studied in the literature. Several empirical studies suggest that from the perspective of inflationary pressure and macroeconomic stability, it is not the level but the rate of credit growth that matters. Rapid credit growth can fuel consumption and feed inflation and wage growth, which can erode competitiveness and contribute to current account deficits and the build-up of external debt. Consequently, the external vulnerability of the countries in question increases.

The rapid credit expansion and capital inflow in the nontradable sectors (especially housing) might change the composition of final demand. As a result, a significant change in the real exchange rate might occur. Real appreciation and the external deficit might become excessive due to the un-

7 R. Atoyan, op. cit.

8 P. Halmai, V. Vásáry: Real convergence .... op. cit.

9 For details see e.g. R. Atoyan, op. cit.; T. Becker, D. Daianu, Z. Darvas, V. Gligorov, M. Landesmann, P. Petrovic, J. PisaniFerry, D. Rosati, A. Sapir, B. Weder di Mauro, op. cit. 
Table 2

Post-crisis development of potential growth and its factors in \%

\begin{tabular}{lcccccccccccccccc}
\hline & \multicolumn{3}{c}{ Potential growth } & \multicolumn{1}{c}{ Contribution of different factors to potential growth } \\
& 2009 & 2011 & 2013 & 2016 & 2009 & 2011 & 2013 & 2016 & 2009 & 2011 & 2013 & 2016 & 2009 & 2011 & 2013 & 2016 \\
\hline EU15 & 0.7 & 0.8 & 0.8 & 1.1 & -0.2 & 0.0 & -0.1 & 0.0 & 0.4 & 0.4 & 0.4 & 0.5 & 0.4 & 0.4 & 0.5 & 0.6 \\
\hline EU10 & 2.9 & 2.1 & 2.2 & 2.3 & 0.3 & -0.2 & -0.1 & -0.1 & 1.5 & 1.3 & 1.3 & 1.2 & 1.1 & 0.9 & 1.0 & 1.2 \\
\hline CE5 & 3.2 & 2.4 & 2.2 & 2.2 & 0.6 & 0.0 & 0.0 & -0.1 & 1.5 & 1.3 & 1.2 & 1.1 & 1.2 & 1.0 & 1.0 & 1.2 \\
\hline B3 & 0.6 & 0.3 & 2.3 & 2.1 & -1.0 & -1.4 & 0.1 & -0.4 & 0.9 & 1.1 & 1.4 & 1.3 & 0.8 & 0.6 & 0.9 & 1.2 \\
\hline SE2 & 2.7 & 1.8 & 2.2 & 2.7 & -0.3 & -0.5 & -0.1 & 0.2 & 1.9 & 1.5 & 1.5 & 1.4 & 1.1 & 0.7 & 0.8 & 1.1 \\
\hline EU27 & 0.9 & 0.9 & 0.9 & 1.2 & -0.1 & 0.0 & -0.1 & 0.0 & 0.5 & 0.5 & 0.5 & 0.5 & 0.5 & 0.4 & 0.5 & 0.7 \\
\hline
\end{tabular}

Source: own calculation.

justified overly optimistic expectations of economic agents and ill-advised economic policies. ${ }^{10}$ Taking into account the "built-in" vulnerabilities (rapid credit growth in the private sector leading to strong real effective exchange rate appreciation and large current account deficits), we can argue that these might have resulted in a slowdown even without the crisis.

\section{Labour and TFP}

Real appreciation adversely affected the cost competitiveness of potential growth's labour component. There was a significant increase in structural unemployment, and rigidities in the labour market became apparent. These developments may all contribute to the permanent destruction of human capital and thus further losses to the level of potential growth.

The strong TFP growth in the region can be partly attributed to transitional factors such as the institutional changes compelled by EU integration. Therefore, this level of growth is not sustainable over the longer term. What is more, due to a number of factors, e.g. the slower pace of productivity-enhancing structural reforms, rigidities in the economy, corruption and an absence of innovation, there were clear signs of a slowdown in TFP growth even before the financial crisis. The crisis itself and the resulting financial constraints further accentuated these signs, though significant differences among the countries persist.

\section{External openness}

EU integration was one of the most important elements of the region's growth model. The vision of EU integration and EU accession talks drove reform and yielded institutional, le-

10 R. Atoyan, op. cit. gal and behavioural changes. As a consequence of this integration process, all of the EU10 countries achieved deep financial and trade integration with the EU. The export dynamism of the region decreased after accession, and domestic demand (fuelled by cheap credit) grew in importance, resulting in severe imbalances. In small open economies, only export-oriented growth can be sustainable in the long run. Due to the region's general openness, the sharp slowdown in their export markets during the crisis is a major reason for output recession. As a result, the region's current accounts dramatically worsened.

\section{Catching-up process}

We have already seen that many EU10 countries had become increasingly vulnerable before the financial crisis, indicating that the region's pre-crisis growth model is unsustainable. Catching-up is necessarily accompanied by real appreciation. However, if it exceeds its equilibrium level, the economy will overheat, causing unit labour costs to rise and competitiveness to decrease. Wage increases exceeding the level of productivity improvement cannot be sustained over the long term. There is no doubt that the drastically reduced potential growth of the new member states over the mediumterm period will have important consequences for their real economic convergence to the EU average.

\section{Potential growth after the financial crisis}

The EU10 countries were particularly hard hit by the crisis. The strong impact of the crisis on the region can be mainly attributed to "built-in" vulnerabilities: unprecedented current account imbalances in a number of EU10 countries before the crisis, rapid credit expansion, asset bubbles in non-tradable sectors, rapid real exchange rate appreciation, a lack of flexibility in the countries with fixed exchange rates, the strong reliance on external inflows of capital, large debts de- 
Figure 1

Pre- and post-crisis development of the investment ratio

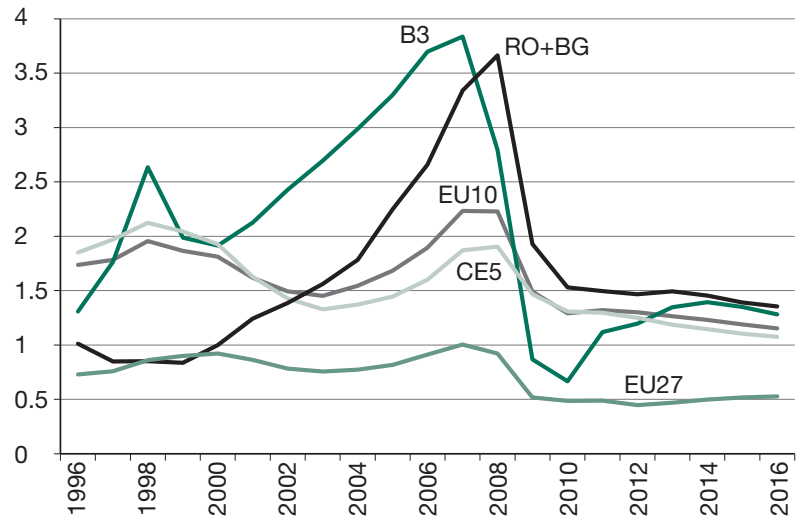

Source: ?

nominated in foreign currencies and fiscal policies that were often too loose.

There were two main channels through which the financial crisis influenced the performance of the EU10: trade and financial integration. First, the fall in foreign demand for EU10 exports (demand-side factors) is a major reason for output recession. Second, the massive foreign capital inflows suddenly stopped or even reversed. Investment levels dropped, which in combination with a wave of bankruptcies and economic restructuring led to a reduction of capital stock and a lowering of potential growth in the short and medium run. In the long run, the negative implications of the crisis on investment may continue if the cost of capital remains permanently higher due to changed risk perceptions. All of these factors may have unfavourable effects on investment, especially with regard to intangible investments (e.g. R\&D. Such a decrease may have significant impacts on the growth of TFP and output. On the other hand, structural unemployment may further increase as a result of the hysteresis effect. ${ }^{11}$ The consequence may be potential growth which is well below the former rate. The medium-term effects (i.e. until 2016) of the crisis on potential growth and its factors as regards the examined countries are given in Table 2.

The main features of potential growth in the EU10 in the crisis years and in the medium-term following the crisis can be summarised in the following points:

- The rate of potential output growth has been decreasing since the onset of the financial crisis. At the same time, the additional dynamism of the EU10 relative to the EU15 is also decreasing; while the difference be-

11 See Blanchard et al., 1989.
Figure 2

Contribution of capital to potential output growth in \%

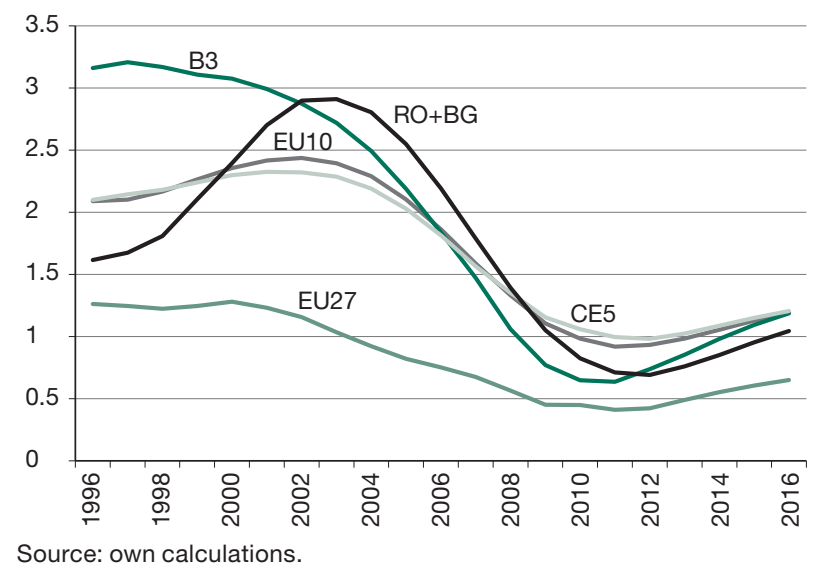

tween their rates of potential growth was $2.2-2.7 \%$ in the years preceding the crisis, it will decline to nearly $1 \%$ by 2016 . All of these factors demonstrate the unsustainable nature of the EU10's pre-crisis growth model. The catching-up potential of the EU10 has significantly decreased, and the strong dynamism of real convergence observed since 2003 has moderated to about $40 \%$ of its former level.

- Large differences can be observed with regard to the performance of country subgroups. The decline of the CE5 group leaves it somewhat off the EU10 average, while the drop in the performance of the B3 group in the crisis years has been dramatic. These tendencies underline the importance of avoiding vulnerability (especially with regard to current account imbalances). The vulnerability of the B3 and SE2 countries may explain their dramatically declining rates of potential growth. (We should mention that although Hungary belongs to the CE5, it is characterised by similar vulnerability and unfavourable potential growth performance.) Finally, we argue that since the outbreak of the crisis, no convergence can be observed in the vulnerable EU10 countries relative to the more developed EU member states, indicating a convergence crisis.

- Structural unemployment moderately increases in the EU10 countries (see Figure 1). Labour's contribution is negative again, and the B3 countries have the worst ratios in this regard.

- The decline of the investment ratio is extraordinary, especially in the B3 and SE2 countries (see Figure 1). The reversal of foreign capital inflow and the necessary adjustment of the current account was accompanied in 
Figure 3

Contribution of TFP to potential output growth in $\%$

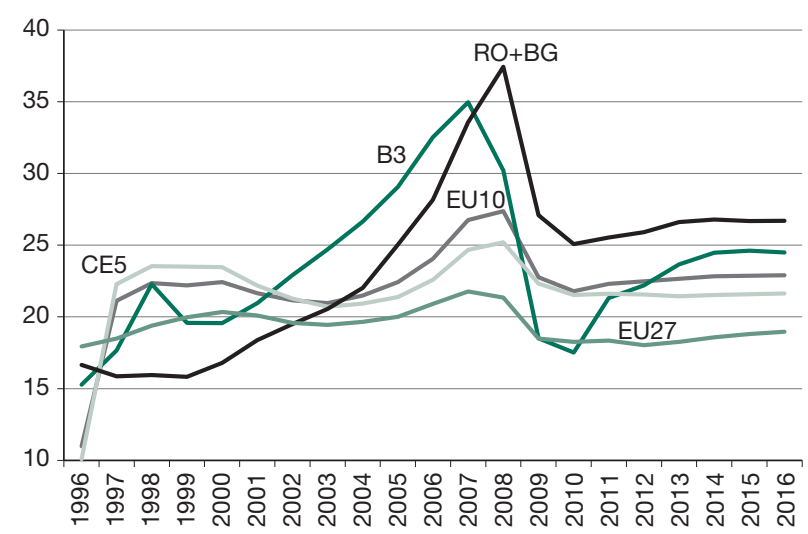

Source: own calculations.

certain cases by a decrease exceeding $20 \%$ of actual growth. In parallel to the decreasing accumulation of capital, capital's contribution to potential growth also declined remarkably. The growth accounting indicates that this factor contributed the most to the post-crisis decline of potential growth in the EU10 (see Figure 2).

- The unfavourable development of total factor productivity further reinforces the negative trends described above (see Figure 3). Its "transition buoyancy" had already slowed down at the time of accession. The erosion of this structurally important productivity factor has continued in the post-crisis period. This in turn is an unfavourable trend as regards the future growth and catching up possibilities of the EU10 countries.

\section{Prospects: towards a new growth model?}

Several policy suggestions emerge from the preceding analysis. It is evident that the pre-crisis growth model cannot ensure the required level of growth. A revised or an entirely new growth model may be needed for the region. As we have seen, none of the factors of potential growth will reach their pre-crisis levels in the medium term (see Figure 4 for a summary). The risk of a structural break in the growth conditions is high. Recovery may be characterised by a long-lasting slow growth period and a decrease in the growth rate of potential GDP. (In order to quantify these trends, alternative simulations are necessary.) While a full rebound is theoretically possible, it seems highly unlikely.

As regards potential growth, the crisis and the period following the crisis may bring further significant changes such as a permanently higher level of structural unemployment, a permanent decrease in the rate of capital accumulation due to a
Figure 4

Development of potential output growth in the EU10, 1996-2016

in $\%$

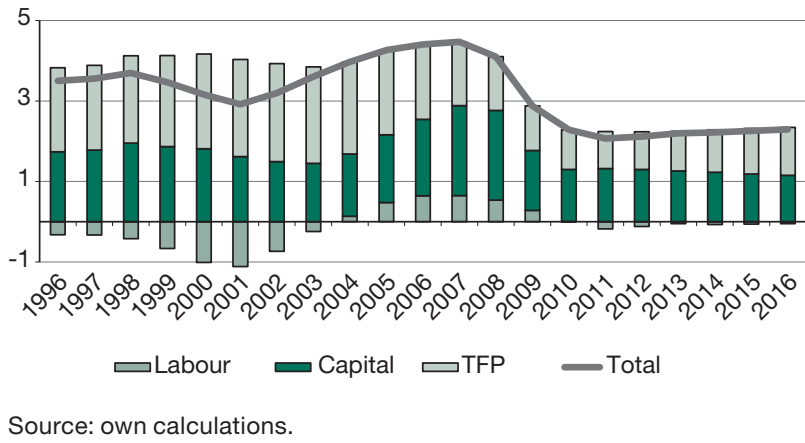

permanent increase in capital costs and a lower level of TFP. We argue that the EU10 countries need a new growth model and the changes referred to above should inevitably be addressed when shaping the new model.

This should be done along three guidelines. First, domestic savings in the EU10 should be increased. This would mitigate the external vulnerability of the countries in question. Note, however, that an upward adjustment of domestic savings rates may result in a drop in domestic demand. Second, radical structural reforms (aimed at increasing potential growth) are needed. Labour's negative contribution trend in particular should be addressed. A more flexible labour supply and an improved capital accumulation ability may result in increased TFP levels. At the same time, however, successful structural reforms may further increase the region's attractiveness for capital inflows, which could lead to the same macroeconomic problems the EU10 had before the crisis. Third, the EU10 should pursue more balanced economic growth. As growth has been driven mainly by large absorption booms, a significant rebalancing towards greater reliance on tradable sectors is needed.

In sum, we can argue that the growth (and catching-up) model of the new member states that worked in the past is not sustainable any more. Strengthening or reviving potential growth and the catching-up potential requires broad structural reforms. European integration may provide an anchor, as it can facilitate growth-promoting structural reforms and sustainable public finance through the development of institutional mechanisms. However, in addition to the internal problems of European integration, the "reform fatigue" characterising the societies of the new member states and the "new populism" in economic policy makes it harder to achieve meaningful reforms. 